\title{
Tea Seed Oil Prevents Obesity, Reduces Physical Fatigue, and Improves Exercise Performance in High-Fat-Diet-Induced Obese Ovariectomized Mice
}

\author{
Yu-Tang Tung ${ }^{1,2,+} \mathbb{D}$, Yi-Ju Hsu $^{3,+}$, Yi-Wen Chien ${ }^{1,4,5} \mathbb{\infty}$, Chi-Chang Huang ${ }^{1,3}$, \\ Wen-Ching Huang ${ }^{6, *}$ and Wan-Chun Chiu ${ }^{4,5, *(D)}$ \\ 1 Graduate Institute of Metabolism and Obesity Sciences, Taipei Medical University, Taipei 11031, Taiwan; \\ f91625059@tmu.edu.tw (Y.-T.T.); ychien@tmu.edu.tw (Y.-W.C.); john5523@ntsu.edu.tw (C.-C.H.) \\ 2 Nutrition Research Center, Taipei Medical University Hospital, Taipei City 11031, Taiwan \\ 3 Graduate Institute of Sports Science, National Taiwan Sport University, Taoyuan 33301, Taiwan; \\ 1041302@ntsu.edu.tw \\ 4 School of Nutrition and Health Sciences, Taipei Medical University, Taipei 11031, Taiwan \\ 5 Research Center of Geriatric Nutrition, College of Nutrition, Taipei Medical University, Taipei 11031, Taiwan \\ 6 Department of Exercise and Health Science, National Taipei University of Nursing and Health Sciences, \\ Taipei 11219, Taiwan \\ * Correspondence: wenching@ntunhs.edu.tw (W.-C.H.); wanchun@tmu.edu.tw (W.-C.C.); \\ Tel.: +886-2-2822-7101 (ext. 7721) (W.-C.H.); +886-2-2736-1661 (ext. 6561) (W.-C.C.) \\ + These authors contributed equally to this work.
}

Academic Editor: Francesca Mancianti

Received: 15 February 2019; Accepted: 5 March 2019; Published: 11 March 2019

\begin{abstract}
Menopause is associated with changes in body composition (a decline in lean body mass and an increase in total fat mass), leading to an increased risk of metabolic syndrome, nonalcoholic fatty liver disease, and heart disease. A healthy diet to control body weight is an effective strategy for preventing and treating menopause-related metabolic syndromes. In the present study, we investigated the effect of long-term feeding of edible oils (soybean oil (SO), tea seed oil (TO), and lard oil (LO)) on female ovariectomized (OVX) mice. SO, TO, and LO comprise mainly polyunsaturated fatty acids (PUFA), monounsaturated fatty acids (MUFA), and saturated fatty acids (SFA), respectively. However, there have been quite limited studies to investigate the effects of different fatty acids (PUFA, MUFA, and SFA) on physiological adaption and metabolic homeostasis in a menopausal population. In this study, 7-week-old female Institute of Cancer Research (ICR) mice underwent either bilateral laparotomy (sham group, $n=8$ ) or bilateral oophorectomy (OVX groups, $n=24$ ). The OVX mice given a high-fat diet (HFD) were randomly divided into three groups: $\mathrm{OVX}+\mathrm{SO}, \mathrm{OVX}+\mathrm{TO}$, and $\mathrm{OVX}+\mathrm{LO}$. An HFD rich in SO, TO, or LO was given to the OVX mice for 12 weeks. Our findings revealed that the body weight and relative tissues of UFP (uterus fatty peripheral) and total fat (TF) were significantly decreased in the OVX+TO group compared with those in the $\mathrm{OVX}+\mathrm{SO}$ and $\mathrm{OVX}+\mathrm{LO}$ groups. However, no significant difference in body weight or in the relative tissues of UFP and TF was noted among the OVX+SO and OVX+LO groups. Furthermore, mice given an HFD rich in TO exhibited significantly decreased accumulation of liver lipid droplets and adipocyte sizes of UFP and brown adipose tissue (BAT) compared with those given an HFD rich in SO or LO. Moreover, replacing SO or LO with TO significantly increased oral glucose tolerance. Additionally, TO improved endurance performance and exhibited antifatigue activity by lowering ammonia, blood urea nitrogen, and creatine kinase levels. Thus, tea seed oil (TO) rich in MUFA could prevent obesity, reduce physical fatigue, and improve exercise performance compared with either SO (PUFA)- or LO(SFA)-rich diets in this HFD-induced obese OVX mice model.
\end{abstract}

Keywords: menopause; tea seed oil; exercise performance; polyunsaturated fatty acids; monounsaturated fatty acids; saturated fatty acids 


\section{Introduction}

Menopause is usually associated with an increase in body weight and body fat accumulation in the waist region, leading to an increased risk of metabolic syndrome, nonalcoholic fatty liver disease (NAFLD), and heart disease [1-4]. Premenopausal women exhibit a lower risk of cardiovascular disease than men with the same body mass index, which may be because estrogen prevents liver fat accumulation and stimulates fat oxidation, thereby preventing insulin resistance [5-11]. Recent studies have demonstrated that mice with estrogen receptor alpha (ER $\alpha)$ mutations, ovariectomized (OVX) rodents, mice with global ER $\alpha$ knockout, and mice lacking aromatase may undergo loss of estrogen signaling, thereby leading to an increase in liver fat [12-16]. Mittendorfer et al. showed that estrogen deficiency leads to redistribution of body fat and accumulation of visceral fat, which may affect NAFLD development and progression [7]. Exogenous estrogen was demonstrated to prevent many menopause-related metabolic abnormalities; however, long-term hormone replacement therapy may increase the risk of breast cancer [17]. Lifestyle changes, including healthy diets and regular exercise to reduce body weight, are the strategies for preventing and treating menopause-related metabolic syndromes $[18,19]$.

Tea seed oil (TO) is an edible oil obtained by squeezing mature seeds of tea (Camellia oleifera), and its fatty acid composition is similar to that of olive oil. Its monounsaturated fatty acid (MUFA) content is higher than that of olive oil, and its unsaturated fatty acid content fully complies with international nutritional standards for the Omega diet [20]. Besides this, a previous study demonstrated that hydroxytyrosol and tyrosol in olive oil have remarkable antioxidative and anti-inflammatory effects against reactive oxygen species (ROS)-induced damage [21]. Tea seed oil contains multifarious functional ingredients such as saponins, polyphenols, vitamin E, squalene, and flavonoids [22]. Tea seed oil, like olive oil, also has antioxidative ingredients. Long-term intake of TO can considerably lower blood pressure, lower blood lipids, delay atherosclerosis, prevent cardiovascular sclerosis, increase gastrointestinal absorption function, promote hormone secretion of the endocrine glands, prevent a decline in neurological function, improve human immunity, and prevent cancer [23].

Metabolic changes caused by estrogen depletion in OVX rodents have many characteristics similar to changes in menopausal women, including weight gain, increased obesity, adipose tissue inflammation, and fatty liver inflammation [24,25]. These similarities make OVX mice suitable models for studying postmenopausal physiological changes. Therefore, in the present study, we investigated the effect of the following three dietary oils on female OVX mice: soybean oil (SO), which contains $24 \%$ oleic acid and $54 \%$ linoleic acid; TO, which mainly contains $78 \%$ oleic acid (C18:1), 9\% linoleic acid (C18:2), 0.4\% linolenic acid (C18:3), 9\% palmitic acid (C16:0), and 2.0\% stearic acid (C18:0); and lard oil (LO), which contains $24 \%$ palmitic acid (16:0) and $44 \%$ oleic acid (18:1). SO, TO, and LO comprise mainly polyunsaturated fatty acids (PUFA), monounsaturated fatty acids (MUFA), and saturated fatty acids (SFA), respectively. Menopausal symptoms generally include hot flashes, night sweat, sleep problems, anxiety, depression, hormone changes, and fatigue. In clinical survey studies, $86 \%$ of Japanese menopausal women felt tiredness more than once a week, and even $49 \%$ felt it almost every day [26]. The postmenopausal women's exercise tolerance could decrease, associated with the loss of potent estrogens, insulin resistance, and endothelial dysfunction [27]. In addition, declines in physical activity and muscle strength were demonstrated not only in menopausal women [28] but also in OVX and estrogen receptor $\alpha(E R \alpha)$ knockout animal models [29]. In previous studies, nutrient supplementation, such as with soy lecithin and estradiol, resulted in fatigue alleviation and physical activity improvement [30,31].

However, there have been quite limited studies to investigate the effects of different fatty acids (PUFA, MUFA, and SFA) on physiological adaption and metabolic homeostasis in a menopausal population. Therefore, we hypothesized that the long-term consumption of the different fatty acids would exert beneficial effects not only on obesity and glucose regulation but also on exercise performance using an ovariectomy and high-fat diet (HFD)-induced obese mouse model. 


\section{Results}

2.1. Effects of SO, TO, and LO on Food Intake, Body Weight, and Tissue Weights of OVX and HFD-Induced Obese Mice

No significant difference in food intake was observed among the Sham+SO (3.10 $\pm 0.06 \mathrm{~g})$, $\mathrm{OVX}+\mathrm{SO}(2.92 \pm 0.06 \mathrm{~g})$, and OVX+TO (2.91 $\pm 0.06 \mathrm{~g})$ groups. However, the food intake of the OVX+LO group $(2.88 \pm 0.10 \mathrm{~g})$ was significantly lower than those of the other groups $(p<0.05)$. The initial body weights were $32.9 \pm 0.08,33.9 \pm 0.08,33.7 \pm 0.08$, and $33.8 \pm 0.07 \mathrm{~g}$ in the Sham $+\mathrm{SO}$, $\mathrm{OVX}+\mathrm{SO}, \mathrm{OVX}+\mathrm{TO}$, and $\mathrm{OVX}+\mathrm{LO}$ groups, respectively, and it did not significantly differ among the groups $\left(\mathrm{F}(3,28)=0.345, p=0.786, \eta^{2}=0.137\right)$. After supplementation and high-fat diet induction (Figure 1), a significant difference was observed among groups $\left(F(3,28)=8.956, p=0.001, \eta^{2}=0.576\right)$, and body weight gain was significantly higher in the OVX+SO group than in the Sham+SO group $(p<0.05)$. However, the body weight in the OVX+TO group was significantly decreased compared with that in the $\mathrm{OVX}+\mathrm{SO}$ and $\mathrm{OVX}+\mathrm{LO}$ groups $(p<0.05)$. As shown in Table 1 , the relative tissue weights (liver, heart, lung, and brown adipose tissue (BAT)) of the mice in the OVX+SO group were significantly lower than those of the Sham+SO group. Also, uterus fatty peripheral (UFP) and total fat (TF) contents in the OVX+SO group were higher than those in the Sham+SO group $(p<0.05)$. However, the relative tissue weights of the liver, heart, lung, muscle, and BAT mass were significantly elevated in the OVX+TO group, whereas the relative tissue weights of UPF and TF were decreased compared with these weights in the OVX+SO and OVX+LO groups.

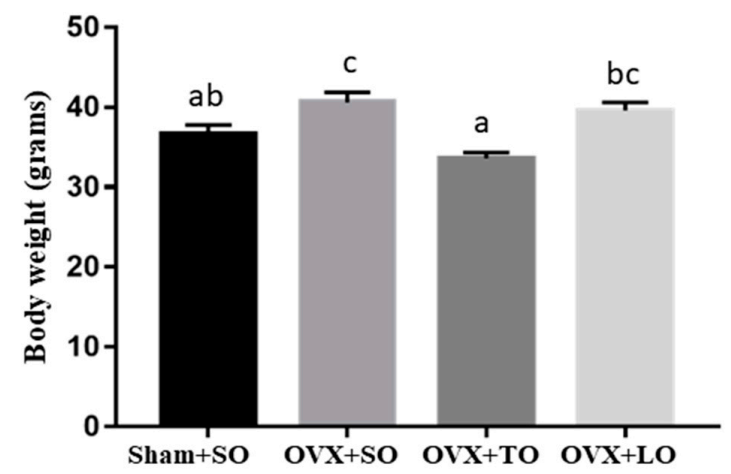

Figure 1. Effect of soybean oil (SO), tea oil (TO), and lard oil (LO) on body weight in ovariectomized and high-fat-diet-induced obese mice at the end of the experiment. Data are presented as mean $\pm \mathrm{SEM}$, $n=8$ mice/group. Bars with different letters $(\mathrm{a}, \mathrm{b}, \mathrm{c})$ indicate a significant difference at $p<0.05$ determined using one-way ANOVA.

Table 1. Effects of soybean oil (SO), tea seed oil (TO), and lard oil (LO) on the relative tissue weights in ovariectomized (OVX) and high-fat-diet-induced obese mice.

\begin{tabular}{|c|c|c|c|c|}
\hline Characteristic & Sham+SO & $\mathrm{OVX}+\mathrm{SO}$ & OVX+TO & OVX+LO \\
\hline Relative liver weight (\%) & $4.02 \pm 0.16^{b}$ & $3.59 \pm 0.07^{a}$ & $4.09 \pm 0.16^{b}$ & $3.54 \pm 0.11^{a}$ \\
\hline Relative kidney weight (\%) & $1.03 \pm 0.06^{\mathrm{a}}$ & $0.84 \pm 0.02^{a}$ & $0.93 \pm 0.05^{a}$ & $0.86 \pm 0.06^{\mathrm{a}}$ \\
\hline Relative heart weight (\%) & $0.44 \pm 0.02^{b}$ & $0.40 \pm 0.01^{a}$ & $0.47 \pm 0.01^{b}$ & $0.42 \pm 0.02^{a}$ \\
\hline Relative lung weight (\%) & $0.56 \pm 0.03^{b}$ & $0.51 \pm 0.03^{a}$ & $0.64 \pm 0.02^{b}$ & $0.54 \pm 0.02^{a}$ \\
\hline Relative muscle weight (\%) & $0.89 \pm 0.02^{b, c}$ & $0.87 \pm 0.03^{a, b}$ & $0.98 \pm 0.02^{c}$ & $0.83 \pm 0.03^{a}$ \\
\hline Relative BAT weight (\%) & $0.23 \pm 0.01^{\mathrm{c}}$ & $0.18 \pm 0.00^{a}$ & $0.22 \pm 0.01^{b}$ & $0.19 \pm 0.01^{\mathrm{a}}$ \\
\hline Relative UPF weight (\%) & $4.31 \pm 0.62^{a}$ & $6.07 \pm 0.65^{b}$ & $4.76 \pm 0.50^{\mathrm{a}, \mathrm{b}}$ & $5.72 \pm 0.23^{a, b}$ \\
\hline Relative TF weight (\%) & $7.96 \pm 0.28^{\mathrm{a}, \mathrm{b}}$ & $9.41 \pm 0.64^{b}$ & $7.19 \pm 0.32^{\mathrm{a}}$ & $9.17 \pm 0.12^{b}$ \\
\hline
\end{tabular}

Data are presented as mean $\pm \mathrm{SEM}, n=8$ mice/group. Different letters $(\mathrm{a}, \mathrm{b}, \mathrm{c})$ in the same row indicate a significant difference at $p<0.05$ determined using one-way ANOVA. Muscle mass includes both gastrocnemius and soleus muscles in the back part of the lower legs. BAT, brown adipose tissue; UFP, uterus fatty peripheral; TF, total fat. 


\subsection{Effects of SO, TO, and LO on Exhaustive Swimming Time and Forelimb Grip Strength in OVX and HFD-Induced Obese Mice}

The basal levels of physical activities before the supplementation and induction are illustrated in Figure 2, and there were no significant differences in exhaustive swimming endurance and grip strength among the groups $\left(\mathrm{F}(3,28)=0.115, p=0.95, \eta^{2}=0.112\right.$ and $\mathrm{F}(3,28)=0.956, p=0.432$, $\eta^{2}=0.194$, respectively). However, the exhaustive swimming endurance and grip strength were significantly different among the groups $\left(\mathrm{F}(3,28)=67.25, p<0.0001, \eta^{2}=0.910\right.$ and $\mathrm{F}(3,28)=5.619$, $p=0.006, \eta^{2}=0.457$, respectively) at the end of experiment (Figure 3 ), and the ovariectomy resulted in significant reductions in the exhaustive swimming time and forelimb grip strength $(p<0.05)$. The exhaustive swimming time was longer in the OVX+TO group than in the OVX+SO and OVX+LO groups $(p<0.0001)$. Thus, the exhaustive swimming time in the OVX+TO group was significantly higher by $49 \%$ and $72 \%$ than those in the OVX+SO and OVX+LO groups, respectively. Therefore, replacing $\mathrm{SO}$ and $\mathrm{LO}$ with $\mathrm{TO}$ can lengthen the exhaustive swimming time in HFD-induced obese OVX mice. In terms of the grip strength, there was no significant difference among the three OVX groups, but the SO, TO, and LO treatments showed a significant decrease by $16-23 \%$ as compared to the Sham + SO group ( $p=0.045,0.032$, and 0.005 , respectively).

(A)

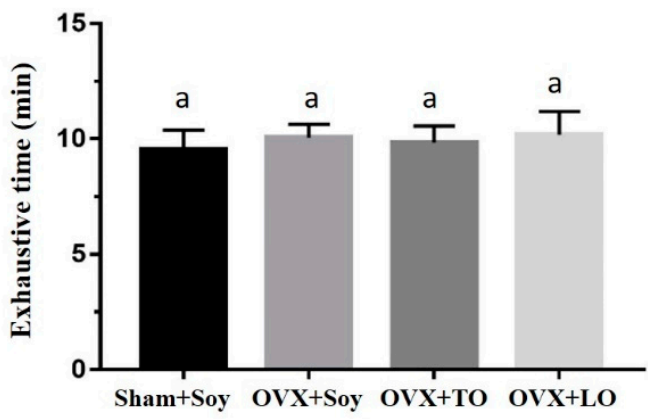

(B)

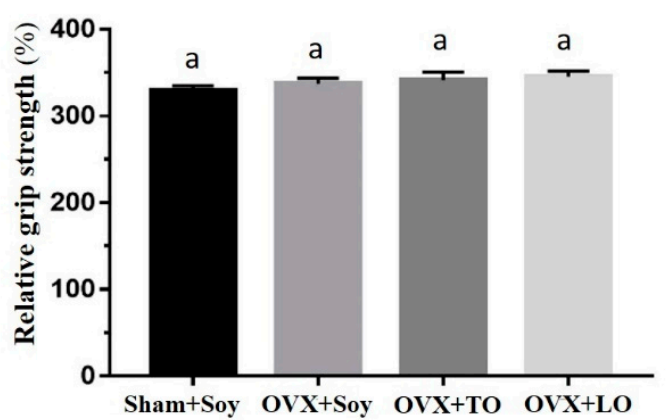

Figure 2. Effects of soybean oil (SO), tea seed oil (TO), and lard oil (LO) on (A) the exhaustive swimming time and (B) forelimb grip strength in ovariectomized and high-fat-diet-induced obese mice at the beginning of the experiment. The exhaustive swimming and grip strength were assessed before the supplementation and induction. Data are presented as mean $\pm \mathrm{SEM}, n=8$ mice/group. Bars with different letters $(a, b)$ indicate a significant difference at $p<0.05$ determined using one-way ANOVA.

(A)

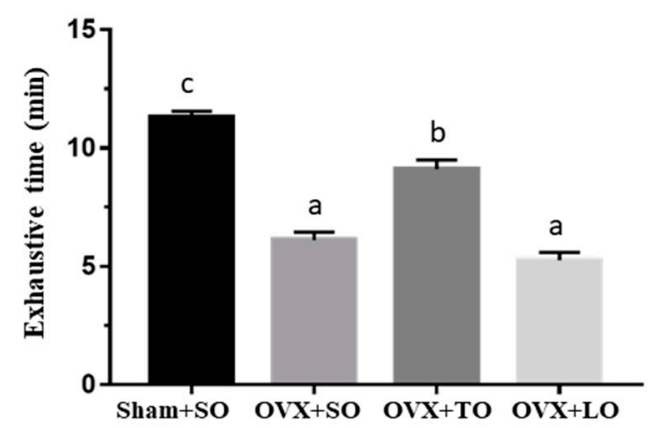

(B)

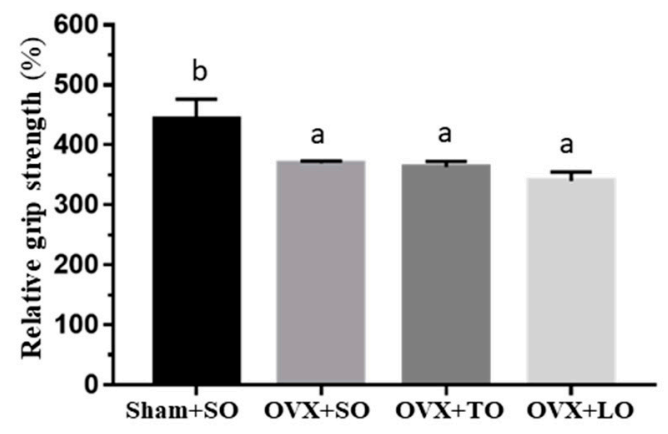

Figure 3. Effects of soybean oil (SO), tea seed oil (TO), and lard oil (LO) on (A) the exhaustive swimming time and (B) forelimb grip strength in ovariectomized and high-fat-diet-induced obese mice at the end of the experiment. After 12 weeks of intervention, exhaustive swimming and grip strength were assessed. Data are presented as mean $\pm \mathrm{SEM}, n=8$ mice/group. Bars with different letters $(\mathrm{a}, \mathrm{b}, \mathrm{c})$ indicate a significant difference at $p<0.05$ determined using one-way ANOVA. 
2.3. Effects of SO, TO, and LO on Lactate, Ammonia, BUN, and CK Levels After the 10 Minutes Swimming Test in OVX and HFD-Induced Obese Mice

The effects of SO, TO, and LO on lactate, ammonia, BUN (Blood Urea Nitrogen), and CK (Creatine Kinase) levels after $10 \mathrm{~min}$ swimming test are shown in Figures 4 and 5. The basal levels of lactate, ammonia, and BUN are illustrated in Figure 4, and no significant difference among the groups in the indicated indices were observed before the swimming test $\left(\mathrm{F}(3,28)=0.481, p=0.698, \eta^{2}=0.049\right.$; $\mathrm{F}(3,28)=0.151, p=0.928, \eta^{2}=0.016$; and $\left.\mathrm{F}(3,28)=0.606, p=0.616, \eta^{2}=0.061\right)$ except for the level of CK $\left(F(3,28)=5.347, p=0.007, \eta^{2}=0.445\right)$. After swimming, the ammonia, BUN, and CK levels demonstrated significant differences among groups $\left(\mathrm{F}(3,28)=4.179, p=0.019, \eta^{2}=0.485\right.$; $\mathrm{F}(3,28)=31.858, p<0.0001, \eta^{2}=0.872 ;$ and $\mathrm{F}(3,28)=4.774, p=0.011, \eta^{2}=0.417$, respectively) but not in the lactate $\left(\mathrm{F}(3,28)=1.912, p=0.16, \eta^{2}=0.223\right)$ (Figure 5). The ammonia and BUN levels in the OVX+SO group were significantly higher by $25 \%(p=0.032)$ and $78 \%(p<0.0001)$, respectively, than those in the Sham $+\mathrm{SO}$ group. However, the ammonia and BUN levels in the OVX+TO group were significantly lower $(21 \%, p=0.027 ; 19 \%, p=0.03$, respectively) than those in the OVX+SO group. Moreover, no significant differences in lactate, ammonia, and BUN levels were noted between the $\mathrm{OVX}+\mathrm{SO}$ and $\mathrm{OVX}+\mathrm{LO}$ groups ( $p=0.984,0.337$, and 0.196 , respectively). However, the CK levels in the OVX+LO group were significantly higher $(58 \%, p=0.012)$ than those in the Sham+SO group. Therefore, replacing SO and $\mathrm{LO}$ with $\mathrm{TO}$ can reduce the ammonia and BUN levels at $10 \mathrm{~min}$ after a swimming test in HFD-induced obese OVX mice.

(A)

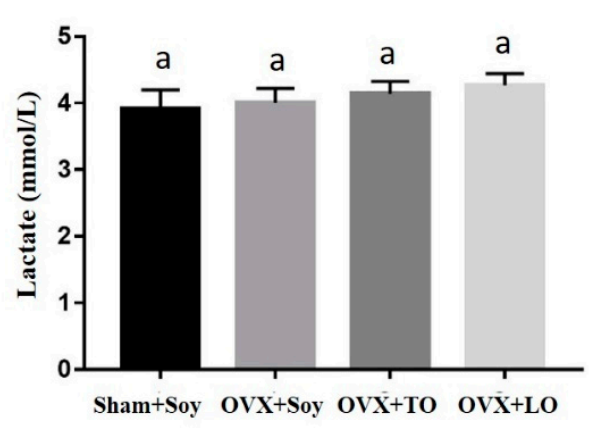

(C)

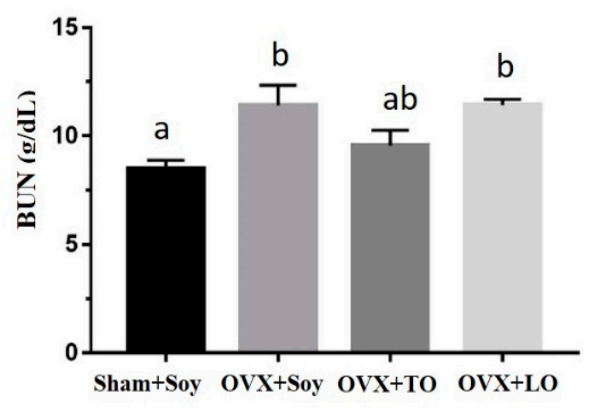

(B)

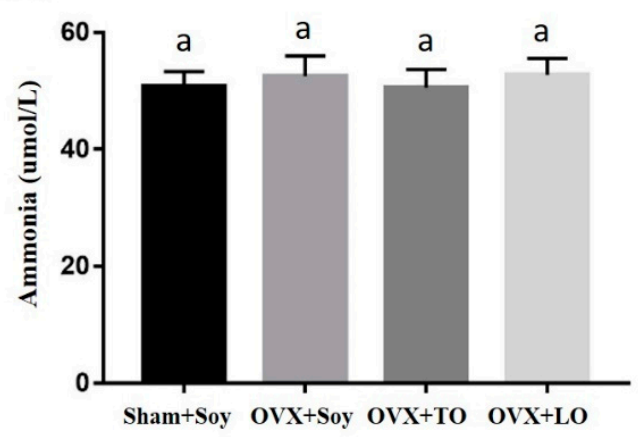

(D)

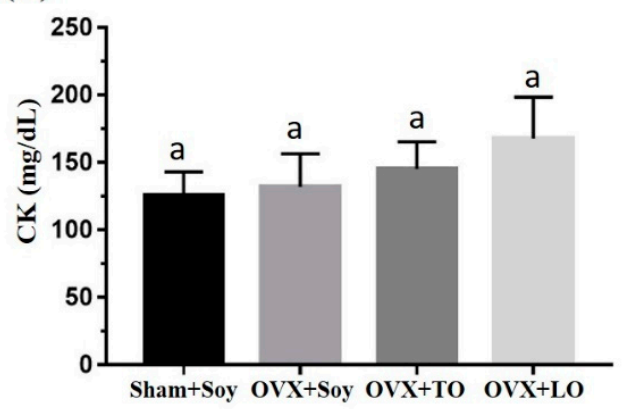

Figure 4. Effects of soybean oil (SO), tea seed oil (TO), and lard oil (LO) on (A) lactate, (B) ammonia, (C) BUN, and (D) CK levels in ovariectomized and high-fat-diet-induced obese mice. After 12 weeks of intervention, fatigue-associated biochemical indices were assessed before a swimming test. Data are presented as mean \pm SEM, $n=8$ mice/group. Bars with different letters $(a, b)$ indicate a significant difference at $p<0.05$ determined using one-way ANOVA. 
(A)

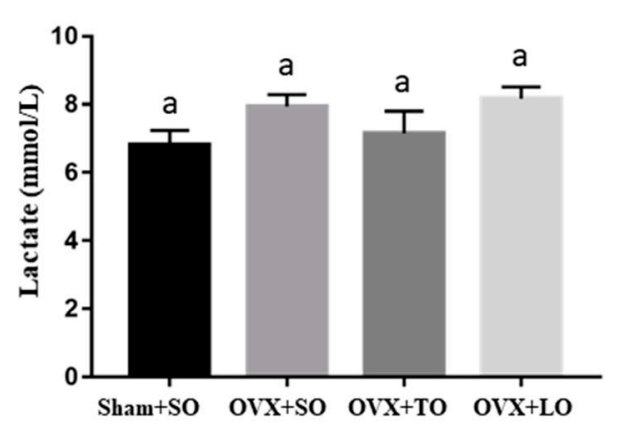

(C)

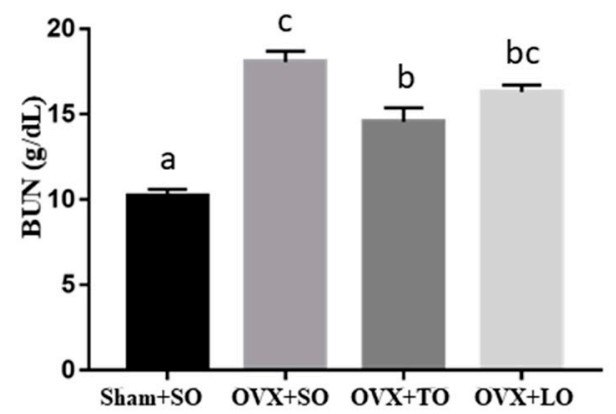

(B)

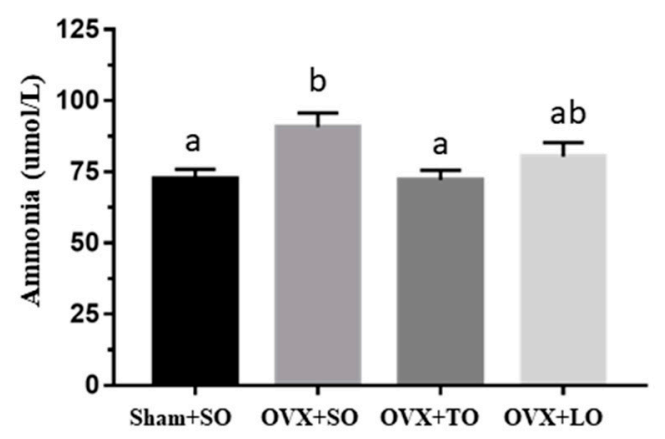

(D)

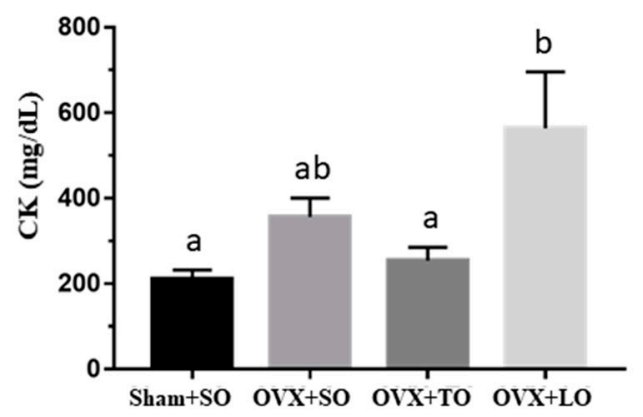

Figure 5. Effects of soybean oil (SO), tea seed oil (TO), and lard oil (LO) on (A) lactate, (B) ammonia, (C) BUN, and (D) CK levels in ovariectomized and high-fat-diet-induced obese mice. After 12 weeks of intervention, fatigue-associated biochemical indices were assessed after a 10 min swimming test. Data are presented as mean $\pm \mathrm{SEM}, n=8$ mice/group. Bars with different letters $(\mathrm{a}, \mathrm{b}, \mathrm{c})$ indicate a significant difference at $p<0.05$ determined using one-way ANOVA.

\subsection{Effects of SO, TO, and LO on Liver Glycogen in OVX and HFD-Induced Obese Mice}

As shown in Figure 6, the liver glycogen content exhibited significant differences among treatments $\left(\mathrm{F}(3,28)=4.9, p=0.01, \eta^{2}=0.524\right)$, and the levels in the OVX+SO, OVX+TO, and OVX+LO groups were lower by $54 \%(p=0.042), 68 \%(p=0.015)$, and $65 \%(p=0.021)$, respectively, than that in the Sham+SO group. Moreover, no significant differences in liver glycogen content was noted among the $\mathrm{OVX}+\mathrm{SO}, \mathrm{OVX}+\mathrm{TO}$, and $\mathrm{OVX}+\mathrm{LO}$ groups.

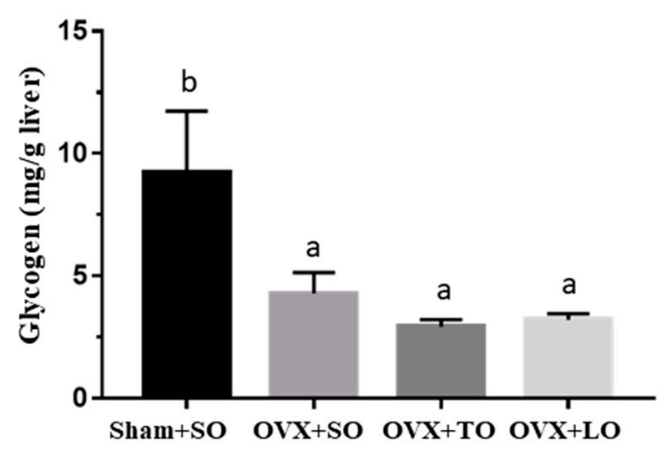

Figure 6. Effects of soybean oil (SO), tea seed oil (TO), and lard oil (LO) on liver glycogen content in ovariectomized and high-fat-diet-induced obese mice. Data are presented as mean \pm SEM, $n=8$ mice/group. Bars with different letters $(a, b)$ indicate a significant difference at $p<0.05$ determined using one-way ANOVA. 


\subsection{Effects of SO, TO, and LO on Oral Glucose Tolerance and AUC in OVX and HFD-Induced Obese Mice}

The effects of SO, TO, and LO on oral glucose tolerance and area under the curve (AUC) in OVX mice are shown in Figure 7A,B, respectively. The $\mathrm{OVX}+\mathrm{SO}$ group exhibited significantly decreased oral glucose tolerance and increased AUC compared with the Sham+SO group. In the glucose tolerance test, shown in Figure 7A, a significant difference was observed for the main effects of both treatment and time $(\mathrm{F}(3,28)=27.1, p<0.0001$, and $\mathrm{F}(4,88)=87.4, p<0.0001$, respectively). However, the OVX+TO group exhibited significantly increased oral glucose tolerance when compared with the OVX+SO group by Tukey post-hoc analysis $(p=0.0001)$. In addition, the interaction effect (treatment $\times$ time) also demonstrated a significant difference $(\mathrm{F}(12,88)=1.88, p=0.049)$. Additionally, there was a significant difference among groups in terms of AUC index $\left(F(3,28)=24.02, p<0.0001, \eta^{2}=0.783\right)$ (Figure 7B), and the Sham+SO group exhibited a significantly lower AUC than did the OVX+SO $(p<0.0001), \mathrm{OVX}+\mathrm{TO}(p=0.003)$, and OVX+LO $(p<0.0001)$ groups. Among the OVX treatments, the OVX+TO group exhibited the smallest AUC compared to the OVX+SO $(p=0.004)$ and OVX+LO $(p=0.042)$ groups.

(A)

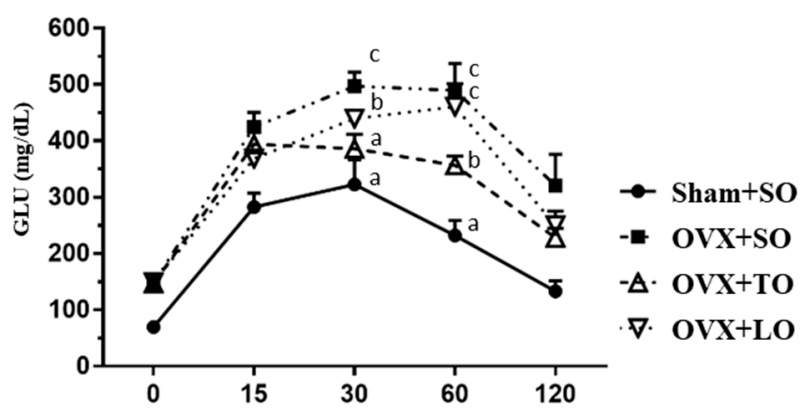

(B)

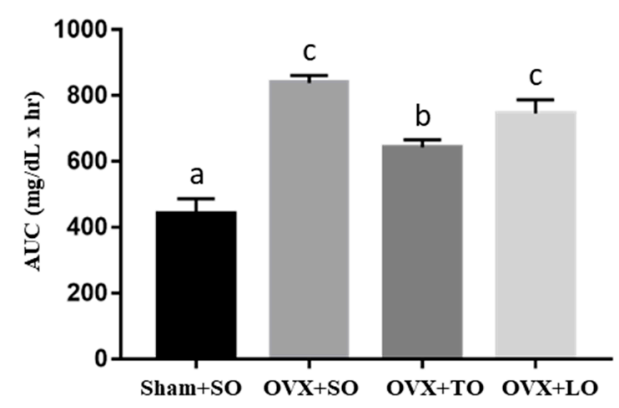

Figure 7. Effects of soybean oil (SO), tea seed oil (TO), and lard oil (LO) on (A) oral glucose tolerance and (B) area under the curve (AUC) in ovariectomized and high-fat-diet-induced obese mice. After 12 weeks of intervention, blood was collected from the caudal artery at the indicated time points for glucose content assessment. Data are presented as mean \pm SEM, $n=8$ mice/group. Bars with different letters $(\mathrm{a}, \mathrm{b}, \mathrm{c})$ indicate a significant difference at $p<0.05$ determined using one-way ANOVA.

2.6. Effects of SO, TO, and LO on Biochemical Variables in OVX and HFD-Induced Obese Mice at the End of the Experiment

The biochemical indices evaluated, namely, AST (aspartate transaminase), ALT (alanine transaminase), TC (Total cholesterol), TG (Triglyceride), BUN, creatinine, ALB (Albumin), TP (Total protein), and LDH (Lactate Dehydrogenase), are shown in Table 2. The TG, BUN, and creatinine levels in the OVX+SO group were significantly higher than those in the Sham+SO group $(\mathrm{F}(3,28)=9.06$, $p=0.001, \eta^{2}=0.576 ; \mathrm{F}(3,28)=5.347, p=0.007, \eta^{2}=0.445 ;$ and $\mathrm{F}(3,28)=3.29, p=0.042, \eta^{2}=0.33$, respectively) and the ALB level in the OVX treatment groups was significantly lower than that in the Sham+SO group $\left(F(3,28)=5.99, p=0.004, \eta^{2}=0.473\right)$. Other biochemical indices, namely insulin, AST, ALT, TC, TP, and LDH, did not significantly differ among the four groups. However, the BUN and creatinine levels in the OVX+TO group were slightly lower $(16 \%, p>0.05 ; 11 \%, p>0.05$, respectively) than that in the OVX+SO group. Notably, the TG level in the OVX+LO group was significantly higher than those in the $\mathrm{OVX}+\mathrm{SO}$ and $\mathrm{OVX}+\mathrm{TO}$ groups. 
Table 2. Effects of soybean oil (SO), tea oil (TO), and lard oil (LO) on biochemical analysis of ovariectomized and high-fat-diet-induced obese mice.

\begin{tabular}{ccccc}
\hline Parameter & Sham+SO & OVX+SO & OVX+TO & OVX+LO \\
\hline Insulin $(\mu \mathrm{IU} / \mathbf{m L})$ & $1.69 \pm 0.11^{\mathrm{a}}$ & $1.11 \pm 0.10^{\mathrm{a}}$ & $1.63 \pm 0.24^{\mathrm{a}}$ & $1.26 \pm 0.17^{\mathrm{a}}$ \\
\hline AST (U/L) & $116 \pm 4^{\mathrm{a}}$ & $131 \pm 8^{\mathrm{a}}$ & $112 \pm 7^{\mathrm{a}}$ & $138 \pm 11^{\mathrm{a}}$ \\
\hline ALT (U/L) & $39 \pm 1^{\mathrm{a}}$ & $50 \pm 2^{\mathrm{a}, \mathrm{b}}$ & $47 \pm 4^{\mathrm{a}, \mathrm{b}}$ & $54 \pm 4^{\mathrm{b}}$ \\
\hline TC (mg/dL) & $57 \pm 2^{\mathrm{a}}$ & $60 \pm 3^{\mathrm{a}, \mathrm{b}}$ & $59 \pm 3^{\mathrm{a}, \mathrm{b}}$ & $68 \pm 3^{\mathrm{b}}$ \\
\hline TG (mg/dL) & $81 \pm 3^{\mathrm{a}}$ & $92 \pm 2^{\mathrm{b}}$ & $89 \pm 3^{\mathrm{a}, \mathrm{b}}$ & $104 \pm 3^{\mathrm{c}}$ \\
\hline BUN (g/dL) & $8.5 \pm 0.3^{\mathrm{a}}$ & $11.4 \pm 0.8^{\mathrm{b}}$ & $9.6 \pm 0.6^{\mathrm{a}, \mathrm{b}}$ & $11.4 \pm 0.2^{\mathrm{b}}$ \\
\hline Creatinine (mg/dL) & $0.23 \pm 0.00^{\mathrm{a}}$ & $0.28 \pm 0.01^{\mathrm{b}}$ & $0.25 \pm 0.01^{\mathrm{a}, \mathrm{b}}$ & $0.24 \pm 0.01^{\mathrm{a}}$ \\
\hline ALB (g/dL) & $3.3 \pm 0.0^{\mathrm{b}}$ & $3.0 \pm 0.1^{\mathrm{a}}$ & $3.1 \pm 0.0^{\mathrm{a}}$ & $3.1 \pm 0.0^{\mathrm{a}}$ \\
\hline TP (g/dL) & $5.3 \pm 0.1^{\mathrm{a}}$ & $5.1 \pm 0.0^{\mathrm{a}}$ & $5.2 \pm 0.1^{\mathrm{a}}$ & $5.3 \pm 0.0^{\mathrm{a}}$ \\
\hline LDH (mg/dL) & $516 \pm 20^{\mathrm{a}}$ & $576 \pm 22^{\mathrm{a}}$ & $540 \pm 27^{\mathrm{a}}$ & $672 \pm 87^{\mathrm{a}}$ \\
\hline
\end{tabular}

After 12 weeks of intervention, the biochemical indices were assessed at the end before mice were sacrificed. Data are presented as mean $\pm \mathrm{SEM}, n=8$ mice/group. Different letters $(\mathrm{a}, \mathrm{b})$ in the same row indicate a significant difference at $p<0.05$ determined using one-way ANOVA. AST, aspartate aminotransferase; ALT, alanine aminotransferase; TC, total cholesterol; TG, triacylglycerol; BUN, blood urea nitrogen; ALB, albumin; TP, total protein; $\mathrm{LDH}$, lactate dehydrogenase.

\subsection{Effects of SO, TO, and LO on Histopathology of Tissues at the End of the Experiment in OVX and} HFD-Induced Obese Mice

The pathological histologies of tissues, namely the liver, kidney, heart, lung, muscle, UFP, and BAT tissues, are shown in Figure 8. The histological observations of the kidney, heart, lung, and muscle of the mice in the $\mathrm{OVX}+\mathrm{SO}, \mathrm{OVX}+\mathrm{TO}$, and $\mathrm{OVX}+\mathrm{LO}$ groups did not significantly differ from those in the $\mathrm{Sham}+\mathrm{SO}$ group. The OVX mice on diet intervention with $\mathrm{SO}$ exhibited marked hepatomegaly and fatty liver formation compared with the sham mice on diet intervention with SO; however, the OVX mice on diet interventions with TO exhibited significant reductions in hepatomegaly and fatty liver formation compared with OVX mice on diet intervention with SO and LO. In addition, large adipocytes of UFP and BAT were markedly increased in the OVX+SO group compared with in the Sham+SO group. However, OVX mice on an HFD rich in SO or LO exhibited significantly larger adipocytes of UFP and BAT than did OVX mice on an HFD rich in TO.
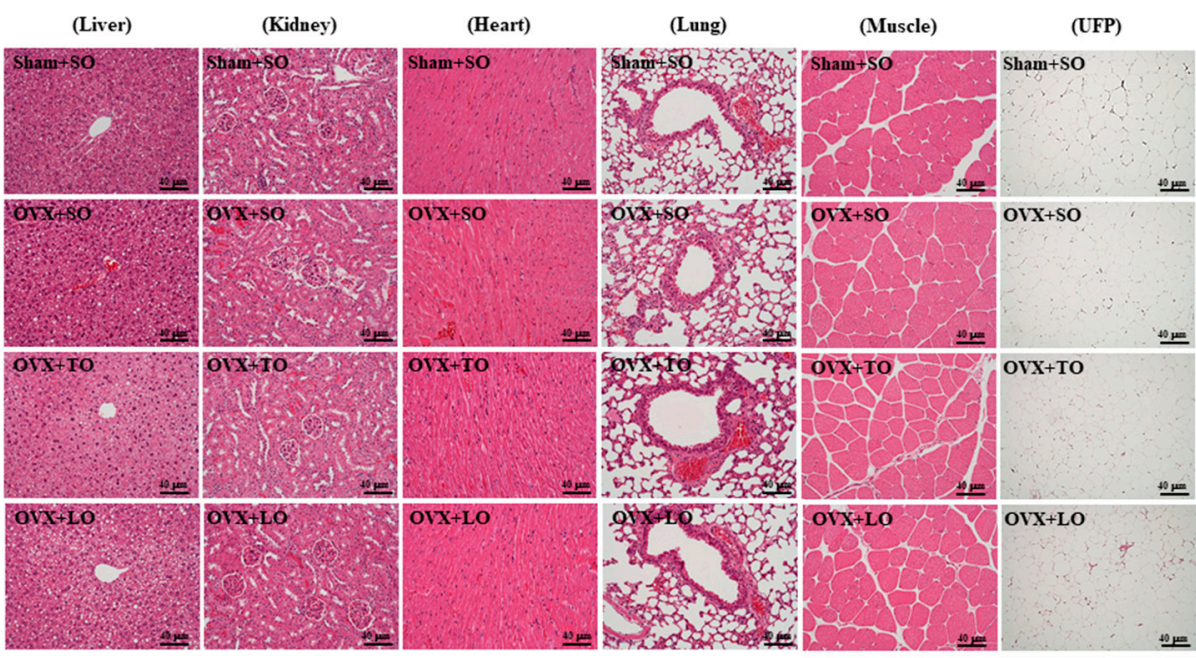

(BAT)

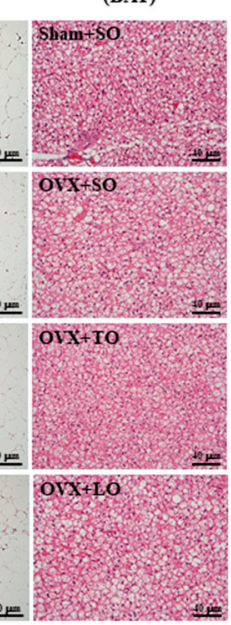

Figure 8. Effects of soybean oil (SO), tea seed oil (TO), and lard oil (LO) on the liver, kidney, heart, lung, muscle, UFP, and BAT tissues in ovariectomized and high-fat-diet-induced obese mice. Specimens were observed using light microscopy. Hematoxylin and eosin stain, magnification: $\times 200$. 


\section{Discussion}

Menopause is associated with changes in body composition (a decline in lean body mass and an increase in TF mass) and rapid loss of bone minerals [31]. Kotani et al. [32] highlighted that menopause significantly accelerates visceral fat accumulation. Lovejoy et al. [33] demonstrated that with age, middle-aged women had increased subcutaneous abdominal fat, whereas menopause is associated with increased body fat and visceral fat in the abdomen, which is associated with a reduction in energy expenditure and fat oxidation. Therefore, estrogens play a vital role in adipose cell metabolism and fat distribution [26]. Dietary ingredients may play a key role in improving insulin sensitivity and reducing the risk of diabetes and its complications [34]. SO, TO, and LO comprise mainly PUFA, MUFA, and SFA, respectively. Ryan et al. [35] reported that in patients with type 2 diabetes, a change from a PUFA diet to MUFA diet reduces insulin resistance and restores endothelium-dependent vasodilatation. Mata et al. [36] demonstrated that at a high fat intake (36\% as calories), a MUFA-rich diet results in less atherogenic lipids compared with either PUFA- or SFA-rich diets. TO has a higher MUFA content than olive oil, and its unsaturated fatty acid content is fully compliant with the international nutritional standards of the Omega diet. In addition, TO contains higher levels of vitamin E (twice as much as that in olive oil) as well as squalene and flavonoids [20].

The OVX mice on an HFD rich in SO consistently exhibited increased body weight compared with the sham mice fed on an HFD rich in SO. This result is in favorable agreement with that of McElroy and Wade [37], who reported that the weight gain caused by ovariectomy is due to an increase in all carcass components (especially in total carcass lipid). However, body weight was significantly decreased in the OVX+TO group compared with in the OVX+SO and OVX+LO groups. Additionally, the relative tissue weights of UFP and TF were higher in the OVX+SO group than in the Sham $+\mathrm{SO}$ group, and replacing SO or LO with TO reduced the relative tissue weights of UFP and TF. However, no significant difference in body weight or in the relative tissue weights of UFP and TF was observed between the OVX+SO and OVX+LO groups. Wang et al. [38] also showed that an HFD rich in LO or SO had no significant effect on the incidences of hyperphagia and obesity. Compared with the SFA-rich diet, the MUFA-rich diet demonstrated an obvious decrease in fat deposition in humans [39]. Moreover, TO can improve human enzyme activities, increase the metabolic rate, and maintain high energy levels [20]. Furthermore, compared with the sham mice that were given an HFD rich in SO, the OVX mice that were given an HFD rich in SO exhibited a marked accumulation of liver lipid droplets and increased adipocyte sizes of UFP and BAT. Estrogen deficiency is associated with liver fat accumulation in women and rodents [3,40]. However, an HFD rich in TO significantly reduced the accumulation of liver lipid droplets and adipocyte sizes of UFP and BAT when compared with an HFD rich in $\mathrm{SO}$ and $\mathrm{LO}$.

In this study, the OVX mice on an HFD diet exhibited significantly increased serum levels of TG, BUN, and creatinine compared with the sham mice on the same HFD diet [41]. Ke et al. [42] demonstrated no differences in BUN level between sham rats and 4-month-old OVX rats but found an increase in the BUN level in the 12-month-old OVX rats compared with sham rats. Post TO supplementation, the treated group exhibited a slight reduction in serum levels of TG, BUN, and creatinine compared with the OVX+SO group. Deng et al. [43] studied the effects of TO intake on the blood lipids of healthy adults and found that consuming $40 \mathrm{~g} /$ day reduced the levels of TG, TC, and LDL-C by 15.9\%, 9.6\%, and 13\%, respectively. Deng et al. [44] also showed that TO could lower both TC and TG levels in male albino Wistar rats. The OVX mice that were given an HFD rich in SO exhibited significantly decreased oral glucose tolerance compared with the sham mice fed on an HFD rich in SO. The OVX mice exhibited metabolic disorders associated with estrogen deficiency, including elevated fasting blood glucose and obesity [3,40,45]. Roger et al. demonstrated increased fasting blood glucose levels in mice 12 weeks after ovariectomy compared with sham-operated mice [24]. However, the OVX+TO group exhibited significantly increased oral glucose tolerance compared with the $\mathrm{OVX}+\mathrm{SO}$ and $\mathrm{OVX}+\mathrm{LO}$ groups. Wang et al. [38] reported that obese rats that were continuously 
given an HFD rich in LO exhibited the highest fasting serum insulin level. However, in the subgroup of overweight subjects, SFA reduced insulin sensitivity (by 24\%) compared with MUFA [34].

To examine the effectiveness of TO in improving the exercise endurance capacity in ovariectomized and HFD-induced obese mice, all animals underwent a swim-to-exhaustion exercise test. Compared with the $\mathrm{OVX}+\mathrm{SO}$ group, the swimming time to exhaustion was significantly prolonged in the $\mathrm{OVX}+\mathrm{TO}$ group, and hence, TO significantly improved the exercise endurance of the test animals. In this study, we found that replacing $\mathrm{SO}$ or $\mathrm{LO}$ with $\mathrm{TO}$ for 12 weeks can reduce blood ammonia, BUN, and CK levels, which are key blood biochemical parameters related to fatigue. Moreover, TO contains a higher squalene content, and Zhao et al. [46] revealed that squalene exhibits antifatigue ability. In addition, according to the previous study, the unsaturated fatty acids in tea oil could show much stronger antioxidative activities [47]. Therefore, we found that the TO could alleviate the indices, including blood ammonia, BUN, and CK, induced by exercise oxidative stress or injury. In addition, energy utilization could also be another factor modulated by TO supplementation. In the glucose tolerance result, the TO could improve the glucose sensitivity as compared to OVX groups with other oil supplementation. Therefore, TO supplementation could enhance exercise endurance, possibly by the beneficial effects of antioxidation and energy utilization. A previous study showed that a diet rich in TO can alleviate oxidative stress and inflammatory markers in women with hypercholesterolemia [48]. TO can alleviate damage to the gastric mucosa by ethanol through reducing lipid peroxidation, apoptosis-related proteins, proinflammatory cytokines, and nitric oxide production and by increasing antioxidant enzyme activities, heat shock proteins, and prostaglandin E2 production [49]. TO can ameliorate ketoprofen-induced gastrointestinal mucosal injury through reductions in inflammation, impairment of the antioxidant system, and oxidative damage [50]. TO can improve acetic-acid-induced colitis through reducing inflammatory damage and lipid peroxidation [22]. Therefore, TO may decrease OVX and high-fat-diet-induced obesity, improve endurance performance, and exhibit antifatigue activity, which may be related to the reduction of oxidative stress and inflammatory response. We also believe that this is an important issue to bring to possible applications to human health promotion. In the current experimental design, the indicated oil was mixed with the AIN-93M recipe to replace the oil components for daily diet uptake. Therefore, we believe that daily TO should be considered as a dietary supplement for human health benefit based on the current postmenopausal animal study.

\section{Materials and Methods}

\subsection{Preparation of Oils}

Commercially available refined SO, TO, and LO were purchased from the Taiwan Sugar Corporation (Tainan, Taiwan), Pinglin District Farmer's Association (New Taipei, Taiwan), and I-Mei Foods Company (Taipei, Taiwan), respectively. All oil samples were stored in sealed containers at $4{ }^{\circ} \mathrm{C}$ until further use.

\subsection{Animals and Experiment Design}

Female Institute of Cancer Research (ICR) mice (age: 6 weeks) purchased from BioLASCO (A Charles River Licensee Corp., Yilan, Taiwan) were kept at $24 \pm 2{ }^{\circ} \mathrm{C}$ under humidity-controlled $(65 \% \pm 5 \%)$ conditions on a $12 \mathrm{~h}$ light/dark cycle. The mice were allowed one week to acclimatize to the environment and diet. The mice were given access to the AIN-93M diet and distilled water ad libitum. This study was approved by the Institutional Animal Care and Use Committee of National Taiwan Sport University, Taoyuan City, Taiwan (LAC-2016-0451). After Zoletil 50 (Virbac, France)/Rompun (Bayer, Germany) anesthesia was administered, the 7-week-old female ICR mice were subjected to either bilateral laparotomy (sham group, $n=8$ ) or bilateral oophorectomy (OVX groups, $n=24$ ). Two weeks after surgery, the OVX mice that were given an HFD were randomly divided into three groups: OVX+SO, OVX+TO, and OVX+LO. The HFD (modified AIN-93M diet) contained $245 \mathrm{~g}$ of cornstarch, $80 \mathrm{~g}$ of maltodextrin, $100 \mathrm{~g}$ of sucrose, $200 \mathrm{~g}$ of casein, $2 \mathrm{~g}$ of L-cystine, $275 \mathrm{~g}$ of oil (SO 
group: $275 \mathrm{~g}$ of SO; TO group: $40 \mathrm{~g}$ of SO and $235 \mathrm{~g}$ of TO; and LO group: $40 \mathrm{~g}$ of SO and $235 \mathrm{~g}$ of LO), $50 \mathrm{~g}$ of cellulose, $35 \mathrm{~g}$ of mineral mixture, $10 \mathrm{~g}$ of vitamin mixture, and $3 \mathrm{~g}$ of choline bitartrate per $\mathrm{kg}$ diet; the energy content of this diet was $4.983 \mathrm{kcal} / \mathrm{g}$, comprising $16.1 \%$ calories from protein, $49.7 \%$ calories from fats, and $34.2 \%$ calories from carbohydrates. After 12 weeks of intervention, the exhaustive swimming, grip strength, glucose tolerance, and fatigue-associated biochemical indices were assessed. The mice were sacrificed, and samples (tissues and serum) were stored at $-80{ }^{\circ} \mathrm{C}$ for further analysis. The liver, kidney, heart, lung, muscle, brown adipose tissue (BAT), uterus fatty peripheral (UFP), and total fat (TF) were collected for weight record and pathological examination. In this study, we conducted outcome evaluations blinded to the group allocation of mice to avoid the effects of personal bias.

\subsection{Exhaustive Swimming Test}

An exhaustive swimming test was conducted according to the method of Kan et al. [51]. The swimming time from the beginning until exhaustion was measured to evaluate endurance performance.

\subsection{Forelimb Grip Strength}

A low-force testing system (Model-RX-5, Aikoh Engineering, Nagoya, Japan) was used to measure the forelimb absolute grip strength, as previously described [52].

\subsection{Fatigue-Associated Biochemical Indices}

Blood samples were collected within $10 \mathrm{~min}$ of the swimming exercise after 12 hours of fasting. Serum was centrifuged for $10 \mathrm{~min}(1500 \mathrm{~g})$ at $4{ }^{\circ} \mathrm{C}$. Lactate, ammonia, blood urea nitrogen (BUN), and creatine kinase (CK) levels were determined to evaluate fatigue-associated changes by using an autoanalyzer (Hitachi 7060, Hitachi, Tokyo, Japan).

\subsection{Tissue Glycogen Determination}

Following the experiments, liver glycogen content was analyzed. Glycogen was analyzed according to our previously described method [52].

\subsection{Histological Staining of Tissues}

Various tissues were collected and fixed in 10\% formalin after the mice were sacrificed. Hematoxylin and eosin staining was performed according to a previously described method by Huang et al. [53].

\subsection{Oral Gavage Glucose Tolerance Test}

The mice underwent fasting for $12 \mathrm{~h}$; fasting blood glucose was analyzed. Subsequently, glucose solution ( $2 \mathrm{~g} / \mathrm{kg}$ body weight) was administered orally, and blood was successively collected at 15, 30, 60, and $120 \mathrm{~min}$. The blood was collected from the caudal artery by needle puncture at the indicated serial time points for glucose level assessment. The glucose content was determined using a glucose meter (ACCU-CHEK ${ }^{\circledR}$, Roche, Indianapolis, IN, USA). Glucose area under the curve $($ AUC $)=0.25 \times($ fasting value $)+0.5 \times($ half-hour value $)+0.75 \times(1 \mathrm{~h}$ value $)+0.5 \times(2 \mathrm{~h}$ value $)$.

\subsection{Blood Biochemical Assessments}

At the end of the experiments, all mice underwent fasting for $12 \mathrm{~h}$, and blood was withdrawn through cardiac puncture. Serum was collected through centrifugation, and the levels of insulin, aspartate aminotransferase (AST), alanine aminotransferase (ALT), total cholesterol (TC), triacylglycerol (TG), BUN, creatinine, albumin (ALB), total protein (TP), and lactate dehydrogenase (LDH) were assessed using an autoanalyzer (Hitachi 7060). 


\subsection{Statistical Analysis}

Experimental data are expressed as mean $\pm \operatorname{SEM}(n=8)$. The parametric one-way ANOVA was employed to calculate the significant differences (physical activities, biochemical indices, and glycogen content) among groups, followed by Tukey multiple range tests, and mixed two-way ANOVA was also applied to the glucose tolerance test. The effect size was calculated as partial eta-squared $\left(\eta^{2}\right)$. Statistical significance was set at $p<0.05$.

\section{Conclusions}

In the present study, we found that replacing $\mathrm{SO}$ and $\mathrm{LO}$ with $\mathrm{TO}$ reduced ovariectomy-induced weight gain, improved liver lipid profiles, and alleviated metabolic syndrome in the postmenopausal condition. Also, TO can improve endurance performance and exhibits antifatigue activity by lowering ammonia, BUN, and CK levels. Thus, the intake of an HFD rich in MUFA from tea seed oil could prevent obesity, reduce physical fatigue, and improve exercise performance compared with the intake of PUFA- or SFA-rich diets in the ovariectomized female mouse model. For practical applications, MUFA, the major fatty acid component of tea seed oil, could be a beneficial alternative option for daily intake or oil replacement for the menopausal population for health promotion purposes.

Author Contributions: W.-C.C. and C.-C.H. designed the model and the computational framework. Y.-J.H. and W.-C.H. performed the measurements. Y.-T.T., Y.-J.H., Y.-W.C., W.-C.H., and W.-C.C. analyzed the data, interpreted the results, prepared the figures, and wrote the manuscript. W.-C.H., W.-C.C., and Y.-J.H. contributed reagents, materials, and analysis platforms.

Funding: This research was funded by the Ministry of Science and Technology (MOST), Taiwan, grant number MOST-106-2320-B-038-033.

Acknowledgments: The authors are grateful to Chien-Chao Chiu for technical assistance in the pathological examination.

Conflicts of Interest: The authors declare no conflict of interest.

\section{References}

1. Davis, S.R.; Castelo-Branco, C.; Chedraui, P.; Lumsden, M.A.; Nappi, R.E.; Shah, D.; Villaseca, P.; Writing Group of the International Menopause Society for World Menopause Day 2012. Understanding weight gain at menopause. Climacteric 2012, 15, 419-429. [CrossRef] [PubMed]

2. Kaaja, R.J. Metabolic syndrome and the menopause. Menopause Int. 2008, 14, 21-25. [CrossRef] [PubMed]

3. Suzuki, A.; Abdelmalek, M.F. Nonalcoholic fatty liver disease in women. Womens Health 2009, 5, $191-203$. [CrossRef] [PubMed]

4. Barrett-Connor, E. Menopause, atherosclerosis, and coronary artery disease. Curr. Opin. Pharmacol. 2013, 13, 186-191. [CrossRef] [PubMed]

5. Lemieux, S.; Prud'homme, D.; Bouchard, C.; Tremblay, A.; Després, J.P. Sex differences in the relation of visceral adipose tissue accumulation to total body fatness. Am. J. Clin. Nutr. 1993, 58, 463-467. [CrossRef] [PubMed]

6. Riant, E.; Waget, A.; Cogo, H.; Arnal, J.F.; Burcelin, R.; Gourdy, P. Estrogens protect against high-fat diet-induced insulin resistance and glucose intolerance in mice. Endocrinology 2009, 150, $2109-2117$. [CrossRef] [PubMed]

7. Mittendorfer, B.; Patterson, B.W.; Klein, S. Effect of sex and obesity on basal VLDL-triacylglycerol kinetics. Am. J. Clin. Nutr. 2003, 77, 573-579. [CrossRef] [PubMed]

8. Roger, V.L.; Go, A.S.; Lloyd-Jones, D.M.; Adams, R.J.; Berry, J.D.; Brown, T.M.; Carnethon, M.R.; Dai, S.; de Simone, G.; Ford, E.S.; et al. American Heart Association Statistics Committee and Stroke Statistics Subcommittee. Heart disease and stroke statistics-2011 update: A report from the American Heart Association. Circulation 2011, 123, e18-e209. [CrossRef] [PubMed]

9. Keil, J.E.; Sutherland, S.E.; Knapp, R.G.; Lackland, D.T.; Gazes, P.C.; Tyroler, H.A. Mortality rates and risk factors for coronary disease in black as compared with white men and women. N. Engl. J. Med. 1993, 329, 73-78. [CrossRef] [PubMed] 
10. Fontaine, K.R.; Redden, D.T.; Wang, C.; Westfall, A.O.; Allison, D.B. Years of life lost due to obesity. JAMA 2003, 289, 187-193. [CrossRef] [PubMed]

11. Martinez, M.N.; Emfinger, C.H.; Overton, M.H.; Hill, S.; Ramaswamy, T.S.; Cappel, D.A.; Wu, K.; Fazio, S.; McDonald, W.H.; Hachey, D.L.; et al. Obesity and altered glucose metabolism impact HDL composition in CETP transgenic mice: A role for ovarian hormones. J. Lipid Res. 2012, 53, 379-389. [CrossRef] [PubMed]

12. Ribas, V.; Nguyen, M.T.; Henstridge, D.C.; Nguyen, A.K.; Beaven, S.W.; Watt, M.J.; Hevener, A.L. Impaired oxidative metabolism and inflammation are associated with insulin resistance in ERalphadeficient mice. Am. J. Physiol. Endocrinol. Metab. 2010, 298, E304-E319. [CrossRef] [PubMed]

13. Bryzgalova, G.; Gao, H.; Ahren, B.; Zierath, J.R.; Galuska, D.; Steiler, T.L.; Dahlman-Wright, K.; Nilsson, S.; Gustafsson, J.A.; Efendic, S.; et al. Evidence that oestrogen receptoralpha plays an important role in the regulation of glucose homeostasis in mice: Insulin sensitivity in the liver. Diabetologia 2006, 49, 588-597. [CrossRef] [PubMed]

14. Jones, M.E.; Thorburn, A.W.; Britt, K.L.; Hewitt, K.N.; Wreford, N.G.; Proietto, J.; Oz, O.K.; Leury, B.J.; Robertson, K.M.; Yao, S.; et al. Aromatase-deficient (ArKO) mice have a phenotype of increased adiposity. Proc. Natl. Acad. Sci. USA 2000, 97, 12735-12740. [CrossRef] [PubMed]

15. Deshaies, Y.; Dagnault, A.; Lalonde, J.; Richard, D. Interaction of corticosterone and gonadal steroids on lipid deposition in the female rat. Am. J. Physiol. 1997, 36, E355-E363. [CrossRef] [PubMed]

16. Picard, F.; Deshaies, Y.; Lalonde, J.; Samson, P.; Labrie, C.; Bélanger, A.; Labrie, F.; Richard, D. Effects of the estrogen antagonist EM-652.HCL on energy balance and lipid metabolism in ovariectomized rats. Int. J. Obes. 2000, 24, 830-840. [CrossRef]

17. Rossouw, J.E.; Anderson, G.L.; Prentice, R.L.; LaCroix, A.Z.; Kooperberg, C.; Stefanick, M.L.; Jackson, R.D.; Beresford, S.A.; Howard, B.V.; Johnson, K.C.; et al. Risks and benefits of estrogen plus progestin in healthy postmenopausal women: Principal results From the Women's Health Initiative randomized controlled trial. JAMA 2002, 288, 321-333. [PubMed]

18. Terao, J. Dietary flavonoids as antioxidants. Forum Nutr. 2009, 61, 87-94. [PubMed]

19. Meydani, M.; Hasan, S.T. Dietary polyphenols and obesity. Nutrients 2010, 2, 737-751. [CrossRef] [PubMed]

20. Li, H.; Zhou, G.Y.; Zhang, H.Y.; Liu, J.A. Research progress on the health function of tea oil. J. Med. Plants Res. 2011, 5, 485-489.

21. Alkhatib, A.; Tsang, C.; Tuomilehto, J. Olive Oil Nutraceuticals in the Prevention and Management of Diabetes: From Molecules to Lifestyle. Int. J. Mol. Sci. 2018, 19, 2024. [CrossRef] [PubMed]

22. Lee, W.T.; Tung, Y.T.; Wu, C.C.; Tu, P.S.; Yen, G.C. Camellia oil (Camellia oleifera Abel.) modifies the composition of gut microbiota and alleviates acetic acid-induced colitis in rats. J. Agric. Food Chem. 2018, 66, 7384-7392. [CrossRef] [PubMed]

23. Wu, X.H.; Huang, Y.F.; Xie, Z.F. Health functions and prospective of camellia oil. Food Sci. Technol. 2005, 5, 94-96.

24. Rogers, N.H.; Perfield, J.W., 2nd.; Strissel, K.J.; Obin, M.S.; Greenberg, A.S. Reduced energy expenditure and increased inflammation are early events in the development of ovariectomy-induced obesity. Endocrinology 2009, 150, 2161-2168. [CrossRef] [PubMed]

25. Vieira Potter, V.J.; Strissel, K.J.; Xie, C.; Chang, E.; Bennett, G.; Defuria, J.; Obin, M.S.; Greenberg, A.S. Adipose tissue inflammation and reduced insulin sensitivity in ovariectomized mice occurs in the absence of increased adiposity. Endocrinology 2012, 153, 4266-4277. [CrossRef] [PubMed]

26. Terauchi, M.; Hiramitsu, S.; Akiyoshi, M.; Owa, Y.; Kato, K.; Obayashi, S.; Matsushima, E.; Kubota, T. Effects of the kampo formula tokishakuyakusan on headaches and concomitant depression in middle-aged women. Evid. Based Complement. Altern. Med. 2014, 2014, 593560. [CrossRef] [PubMed]

27. Lurati, A.R. Menopause and Exercise Intolerance. Nurs. Womens Health. 2017, 21, 130-136. [CrossRef] [PubMed]

28. Bondarev, D.; Laakkonen, E.K.; Finni, T.; Kokko, K.; Kujala, U.M.; Aukee, P.; Kovanen, V.; Sipilä, S. Physical performance in relation to menopause status and physical activity. Menopause 2018, 25, 1432-1441. [CrossRef] [PubMed]

29. Cabelka, C.A.; Baumann, C.W.; Collins, B.C.; Nash, N.; Le, G.; Lindsay, A.; Spangenburg, E.E.; Lowe, D.A. Effects of ovarian hormones and estrogen receptor $\alpha$ on physical activity and skeletal muscle fatigue in female mice. Exp. Gerontol. 2019, 115, 155-164. [CrossRef] [PubMed] 
30. Hirose, A.; Terauchi, M.; Osaka, Y.; Akiyoshi, M.; Kato, K.; Miyasaka, N. Effect of soy lecithin on fatigue and menopausal symptoms in middle-aged women: A randomized, double-blind, placebo-controlled study. Nutr. J. 2018, 17, 4. [CrossRef] [PubMed]

31. Panotopoulos, G.; Ruiz, J.C.; Raison, J.; Guy-Grand, B.; Basdevant, A. Menopause, fat and lean distribution in obese women. Maturitas 1996, 25, 11-19. [CrossRef]

32. Kotani, K.; Tokunaga, K.; Fujioka, S.; Kobatake, T.; Keno, Y.; Yoshida, S.; Shimomura, I.; Tarui, S.; Matsuzawa, Y. Sexual dimorphism of age-related changes in whole-body fat distribution in the obese. Int. J. Obes. Relat. Metab. Disord. 1994, 18, 207-212. [PubMed]

33. Lovejoy, J.C.; Champagne, C.M.; de Jonge, L.; Xie, H.; Smith, S.R. Increased visceral fat and decreased energy expenditure during the menopausal transition. Int. J. Obes. (Lond.) 2008, 32, 949-958. [CrossRef] [PubMed]

34. Risérus, U.; Willett, W.C.; Hu, F.B. Dietary fats and prevention of type 2 diabetes. Prog. Lipid Res. 2009, 48, 44-51. [CrossRef] [PubMed]

35. Ryan, M.; McInerney, D.; Owens, D.; Collins, P.; Johnson, A.; Tomkin, G.H. Diabetes and the Mediterranean diet: A beneficial effect of oleic acid on insulin sensitivity, adipocyte glucose transport and endothelium-dependent vasoreactivity. QJM 2000, 93, 85-91. [CrossRef] [PubMed]

36. Mata, P.; Garrido, J.A.; Ordovas, J.M.; Blazquez, E.; Alvarez-Sala, L.A.; Rubio, M.J.; Alonso, R.; de Oya, M. Effect of dietary monounsaturated fatty acids on plasma lipoproteins and apolipoproteins in women. Am. J. Clin. Nutr. 1992, 56, 77-83. [CrossRef] [PubMed]

37. McElroy, J.F.; Wade, G.N. Short- and long-term effects of ovariectomy on food intake, body weight, carcass composition, and brown adipose tissue in rats. Physiol. Behav. 1987, 39, 361-365. [CrossRef]

38. Wang, X.; Cheng, M.; Zhao, M.; Ge, A.; Guo, F.; Zhang, M.; Yang, Y.; Liu, L.; Yang, N. Differential effects of high-fat-diet rich in lard oil or soybean oil on osteopontin expression and inflammation of adipose tissue in diet-induced obese rats. Eur. J. Nutr. 2013, 52, 1181-1189. [CrossRef] [PubMed]

39. Piers, L.S.; Walker, K.Z.; Stoney, R.M.; Soares, M.J.; O’Dea, K. The influence of the type of dietary fat on postprandial fat oxidation rates: Monounsaturated (olive oil) vs. saturated fat (cream). Int. J. Obes. Relat. Metab. Disord. 2002, 26, 814-821. [CrossRef] [PubMed]

40. Lavoie, J.M.; Pighon, A. NAFLD, estrogens, and physical exercise: The animal model. J. Nutr. Metab. 2012, 2012, 914938. [CrossRef] [PubMed]

41. Maric, C.; Sandberg, K.; Hinojosa-Laborde, C. Glomerulosclerosis and tubulointerstitial fibrosis are attenuated with 17beta-estradiol in the aging Dahl salt sensitive rat. J. Am. Soc. Nephrol. 2004, 15, 1546-1556. [CrossRef] [PubMed]

42. Ke, J.Y.; Kliewer, K.L.; Hamad, E.M.; Cole, R.M.; Powell, K.A.; Andridge, R.R.; Straka, S.R.; Yee, L.D.; Belury, M.A. The flavonoid, naringenin, decreases adipose tissue mass and attenuates ovariectomy-associated metabolic disturbances in mice. Nutr. Metab. (Lond.) 2015, 12, 1. [CrossRef] [PubMed]

43. Deng, P.J.; Zhang, Y.H.; Huang, J.X. A study of the effect of tea seed oil on serum lipid in normal adults. Acta Nutr. Sin. 1993, 3, 289-292.

44. Deng, X.L.; Xie, G.S.; Huang, S.G. Study on the health care oil tea and just the function of lipid. China Oils Fats 2002, 5, 96-98.

45. Carr, M.C. The emergence of the metabolic syndrome with menopause. J. Clin. Endocrinol. Metab. 2003, 88, 2404-2411. [CrossRef] [PubMed]

46. Zhao, Z.D.; Sun, Z. Research progress on natural resources and application of the bioactive substance-Squalene. Chem. Ind. For. Prod. 2004, 24, 107-112.

47. Wang, Y.; Sun, D.; Chen, H.; Qian, L.; Xu, P. Fatty acid composition and antioxidant activity of tea (Camellia sinensis L.) seed oil extracted by optimized supercritical carbon dioxide. Int. J. Mol. Sci. 2011, 12, 7708-7719. [CrossRef] [PubMed]

48. Bumrungpert, A.; Pavadhgul, P.; Kalpravidh, R.W. Camellia oil-enriched diet attenuates oxidative stress and inflammatory markers in hypercholesterolemic subjects. J. Med. Food 2016, 19, 895-898. [CrossRef] [PubMed]

49. Tu, P.S.; Tung, Y.T.; Lee, W.T.; Yen, G.C. Protective effect of camellia oil (Camellia oleifera Abel.) against ethanol-induced acute oxidative injury of the gastric mucosa in mice. J. Agric. Food Chem. 2017, 21, 4932-4941. [CrossRef] [PubMed]

50. Cheng, Y.T.; Wu, S.L.; Ho, C.Y.; Huang, S.M.; Cheng, C.L.; Yen, G.C. Beneficial effects of camellia oil (Camellia oleifera Abel.) on ketoprofen-induced gastrointestinal mucosal damage through upregulation of HO-1 and VEGF. J. Agric. Food Chem. 2014, 62, 642-650. [CrossRef] [PubMed] 
51. Kan, N.W.; Ho, C.S.; Chiu, Y.S.; Huang, W.C.; Chen, P.Y.; Tung, Y.T.; Huang, C.C. Effects of resveratrol supplementation and exercise training on the exercise performance in middle-aged mice. Molecules 2016, 21, 661. [CrossRef] [PubMed]

52. Huang, C.C.; Hsu, M.C.; Huang, W.C.; Yang, H.R.; Hou, C.C. Triterpenoid-rich extract from Antrodia camphorata improves physical fatigue and exercise performance in mice. Evid. Based Complement. Altern. Med. 2012, 2012, 364741. [CrossRef] [PubMed]

53. Huang, W.C.; Lin, C.I.; Chiu, C.C.; Lin, Y.T.; Huang, W.K.; Huang, H.Y.; Huang, C.C. Chicken essence improves exercise performance and ameliorates physical fatigue. Nutrients 2014, 6, 2681-2696. [CrossRef] [PubMed]

Sample Availability: Not Available.

(C) 2019 by the authors. Licensee MDPI, Basel, Switzerland. This article is an open access article distributed under the terms and conditions of the Creative Commons Attribution (CC BY) license (http:// creativecommons.org/licenses/by/4.0/). 